\title{
Why is the presence of autoantibodies against GAD associated with a relatively slow progression to clinical diabetes?
}

\author{
Anette-Gabriele Ziegler ${ }^{1,2}$ (1) $\cdot$ Ezio Bonifacio ${ }^{3,4}$ (D)
}

Received: 25 March 2020 / Accepted: 10 April 2020 / Published online: 26 May 2020

(C) The Author(s) 2020

\author{
Abbreviations \\ CVB Coxsackievirus B \\ GADA GAD antibodies \\ IAA Insulin autoantibody \\ IA-2 Insulinoma-associated antigen-2
}

To the Editor Type 1 diabetes is an autoimmune disease that can be diagnosed by the detection of islet autoantibodies at a pre-symptomatic stage. Autoantibodies associated with type 1 diabetes have been described against five autoantigens: insulin, GAD65, insulinoma-associated antigen-2 (IA-2), zinc transporter 8 (ZnT8) and tetraspanin 7 [1]. Multiple islet autoantibodies are found in the large majority of children who develop type 1 diabetes, whereas patients who develop type 1 diabetes in adulthood often present with only GAD antibodies (GADA). Moreover, patients without GADA are, on average, younger at diagnosis.

Recently, two studies report that the presence of GADA in children with multiple islet autoantibodies is associated with slow progression to clinical type 1 diabetes. The Bavarian Frlda study tested over 90,000 children aged 2-5 years for pre-symptomatic type 1 diabetes (multiple islet autoantibodies) and identified 280 children with a pre-symptomatic disease, 235 of them with

Ezio Bonifacio

ezio.bonifacio@tu-dresden.de

1 Institute of Diabetes Research, Helmholtz Zentrum München, German Research Center for Environmental Health, Munich-Neuherberg, Germany

2 Forschergruppe Diabetes, Technical University Munich, at Klinikum rechts der Isar, Munich, Germany

3 Center for Regenerative Therapies Dresden, Faculty of Medicine Carl Gustav Carus, Technische Universität Dresden, Fetcherstrasse 105, 01307 Dresden, Germany

4 Paul Langerhans Institute Dresden of the Helmholtz Center Munich at University Hospital Carl Gustav Carus and Faculty of Medicine, Technische Universität, Dresden, Germany
GADA [2]. Children with GADA had a significantly lower risk of developing the clinical stage of type 1 diabetes within a 3 year observation period than children with multiple autoantibodies without GADA (HR 0.43 [95\% CI 0.25, 0.75]). The lower risk in the GADA positives was found for both the children with two or with three positive islet autoantibodies. A similar finding was obtained in the TrialNet Path to Prevention Study [3]. Among participants with two autoantibodies, those with GADA had less risk (HR 0.35 [95\% CI 0.22, 0.57]) of type 1 diabetes than those without GADA. The results from these two studies raise the intriguing possibility that GADA may represent a reaction intended to protect the beta cell.

There are additional findings indirectly supporting the hypothesis that the formation of GADA may not be detrimental for the beta cell and may dampen the destructive immune response in type 1 diabetes. GADA alone pose a relatively low risk for type 1 diabetes. There are several GADA-positive diseases or conditions that do not progress to type 1 diabetes unless other diabetes-associated antibodies are present. In animal models, weekly injection of anti-GAD monoclonal antibody into NOD mice led to a delay in the onset of diabetes and a decrease in the severity of insulitis [4], and in humans, the transfer of GADA (or IA-2A) from mothers with type 1 diabetes to offspring provided relative protection against the development of multiple islet autoantibodies in childhood [5].

In considering potential scenarios in which GADA could be mounted to protect the beta cell, it may be helpful to recollect the mimicry between GAD65 and the PEVKEKcontaining 2C protein of the Coxsackievirus B (CVB) 4. Several studies searched for cross-reactivity of autoreactive $\mathrm{T}$ cells and antibodies toward these PEVKEK peptides. Some evidence for mimicry was inconsistently observed, but the PEVKEK-containing region of GAD65 was not more frequently targeted in people with type 1 diabetes than healthy individuals, and the relevance of this sequence similarity is unresolved. We would like to speculate whether the GADA response could indeed be linked to beta cell CVB infection and may protect against disease progression. We have observed that antibodies that develop against CBVs are 
heterogeneous and do not always include a neutralising antiVP1 component in young children [6]. Strikingly, the same study also found that there was a marked difference between the early CVB responses in the children who developed a GAD-dominated autoimmunity and those who developed an insulin-dominated autoimmunity. GAD autoimmunity was associated with the development of neutralising antibodies, whereas early insulin autoimmunity was associated with a neutralising antibody-deficient response. At the time we focused on the deficient response associated with the early insulin autoantibodies (IAAs), suggesting that these children may have been more susceptible to prolonged virus exposure, a scenario that seems consistent with recent stool virome data in the TEDDY (The Environmental Determinants of Diabetes in the Young) study [7]. However, a closer look at the GADAassociated competent response to $\mathrm{CBV}$ may be warranted.

Finally, the question also arises as to whether GADA may be used to delay the progression to type 1 diabetes and how could this be tested? A number of studies have investigated GAD vaccination in mice or people with pre-symptomatic or manifest type 1 diabetes. These trials had mixed success in delaying progression or maintaining residual beta cell function [8]. However, these trials were based on the underlying concept of inducing GAD tolerance and mainly included people who had GAD autoimmunity. No study has specifically given a GAD vaccine to children without GADA. A trial in $\mathrm{IAA}^{+} / \mathrm{IA}-2 \mathrm{~A}^{+}$children who have a particularly rapid diabetes progression $[6,7]$ may be an option to test whether the induction of GADA by vaccination could slow disease progression. Similarly, it may also be cautiously worth considering primary prevention with a GADA-inducing vaccine.

Authors' relationships and activities The authors declare that there are no relationships or activities that might bias, or be perceived to bias, their work.

Funding Information Open Access funding provided by Projekt DEAL.

Contribution Statement Both authors were responsible for drafting the article and revising it critically for important intellectual content. Both authors approved the version to be published.
Open Access This article is licensed under a Creative Commons Attribution 4.0 International License, which permits use, sharing, adaptation, distribution and reproduction in any medium or format, as long as you give appropriate credit to the original author(s) and the source, provide a link to the Creative Commons licence, and indicate if changes were made. The images or other third party material in this article are included in the article's Creative Commons licence, unless indicated otherwise in a credit line to the material. If material is not included in the article's Creative Commons licence and your intended use is not permitted by statutory regulation or exceeds the permitted use, you will need to obtain permission directly from the copyright holder. To view a copy of this licence, visit http://creativecommons.org/licenses/by/4.0/.

\section{References}

1. Bonifacio E (2015) Predicting type 1 diabetes using biomarkers. Diabetes Care 38(6):989-996. https://doi.org/10.2337/dc15-0101

2. Ziegler A-G, Kick K, Bonifacio E et al (2020) Yield of a public health screening of children for islet autoantibodies in Bavaria, Germany. JAMA 323(4):339-351. https://doi.org/10.1001/jama. 2019.21565

3. Jacobsen LM, Bocchino L, Evans-Molina C et al (2020) The risk of progression to type 1 diabetes is highly variable in individuals with multiple autoantibodies following screening. Diabetologia. 63(3): 588-596. https://doi.org/10.1007/s00125-019-05047-w

4. Menard V, Jacobs H, Jun HS, Yoon JW, Kim SW (1999) Anti-GAD monoclonal antibody delays the onset of diabetes mellitus in NOD mice. Pharm Res 16(7):1059-1066. https://doi.org/10.1023/a: 1018939900961

5. Koczwara K, Bonifacio E, Ziegler AG (2004) Transmission of maternal islet antibodies and risk of autoimmune diabetes in offspring of mothers with type 1 diabetes. Diabetes 53(1):1-4. https://doi.org/10.2337/diabetes.53.1.1

6. Ashton MP, Eugster A, Walther D et al (2016 Sep 8) Incomplete immune response to coxsackie B viruses associates with early autoimmunity against insulin. Sci Rep 6(1):32899. https://doi.org/10. 1038/srep32899

7. Vehik K, Lynch KF, Wong MC et al (2019 Dec) Prospective virome analyses in young children at increased genetic risk for type 1 diabetes. Nat Med 25(12):1865-1872. https://doi.org/10.1038/s41591019-0667-0

8. Beam CA, MacCallum C, Herold KC, Wherrett DK, Palmer J, Ludvigsson J, Type 1 Diabetes TrialNet Study Group (2017) GAD vaccine reduces insulin loss in recently diagnosed type 1 diabetes: findings from a Bayesian meta-analysis. Diabetologia. 60(1):43-49. https://doi.org/10.1007/s00125-016-4122-1

Publisher's note Springer Nature remains neutral with regard to jurisdictional claims in published maps and institutional affiliations. 